Article

\title{
Development of a Genetic Algorithm Code for the Design of Cylindrical Buoyancy Bodies for Floating Offshore Wind Turbine Substructures
}

\author{
Victor Benifla ${ }^{1, *(D)}$ and Frank Adam ${ }^{1,2}$ (D) \\ 1 Lehrstuhl für Windenergietechnik, Universität Rostock, Albert-Einstein-Str. 2, 18059 Rostock, Germany; \\ frank.adam@uni-rostock.de \\ 2 GICON-Großmann Ingenieur Consult GmbH, Tiergartenstr. 48, 01219 Dresden, Germany \\ * Correspondence: victor.benifla@uni-rostock.de
}

check for updates

Citation: Benifla, V.; Adam, F. Development of a Genetic Algorithm Code for the Design of Cylindrical Buoyancy Bodies for Floating Offshore Wind Turbine Substructures. Energies 2022, 15, 1181. https://doi.org/ $10.3390 /$ en15031181

Academic Editor: Matthew Hall

Received: 13 October 2021

Accepted: 28 January 2022

Published: 5 February 2022

Publisher's Note: MDPI stays neutral with regard to jurisdictional claims in published maps and institutional affiliations.

Copyright: (C) 2022 by the authors. Licensee MDPI, Basel, Switzerland. This article is an open access article distributed under the terms and conditions of the Creative Commons Attribution (CC BY) license (https:// creativecommons.org/licenses/by/ $4.0 /)$.

\begin{abstract}
The Levelized Cost of Energy for floating offshore wind must decrease significantly to be competitive with fixed offshore wind projects or even with onshore wind projects. This study focuses on the design optimization of cylindrical buoyancy bodies for floating substructures of offshore wind turbines. The presented work is based on a previously studied buoyancy body design that allows an efficient manufacturing process and integration into different substructures. In this study, an optimization framework based on genetic algorithm is developed to parameterize the buoyancy body's geometry and optimize its design in terms of cost, considering loads acting on the structure as well as manufacturing and floater specific dimension restrictions. The implementation of the optimization process is detailed, and tested for a given study case. Two structurally different genetic algorithms are considered in order to compare the results obtained and asses the performance of the presented optimization framework.
\end{abstract}

Keywords: floating offshore wind; buoyancy body; structural analysis; design optimization; genetic algorithm; levelized cost of energy

\section{Introduction}

Offshore wind farms' role in supplying clean energy for the increasing demand is becoming more and more important. Ecological and economical boundary conditions have major influences on further developments of these offshore technologies, especially floating foundations, which have a great potential for offshore wind farms in water depths greater than $40 \mathrm{~m}$. Offshore wind, mainly bottom fixed offshore wind turbines, have thrived worldwide and particularly in Europe due to the Levelized Cost of Energy (LCoE) of this technology that has dropped over the past decades [1]. However, a significant part of the world's offshore wind resource cannot be harvested by conventional bottom fixed offshore wind turbines for technical and economical reasons. The LCoE for floating offshore wind must decrease significantly to be competitive with fixed offshore wind technologies or even with onshore wind projects, in order to tap this newly accessible wind resource.

A floating offshore wind system includes many different components, and one of the most relevant in terms of cost is the floating platform [2]. Therefore, it is important to consider in the early phase of its development an optimized substructure design in terms of production, transport and maintenance costs. Recently, different substructure concepts and modular components have been developed with the aim of reducing the production cost by serializing the fabrication procedure of these components which could be integrated in the primary structure of floating wind turbine foundations. For instance in the previous study [3], a so called Universal Buoyancy Body (UBB) is presented. This particular cylindrical buoyancy body was thought and developed as a modular component in order to be integrated in different floating substructures of different types. 
In the present study, the first part focuses on introducing general knowledge regarding Floating Offshore Wind Turbine (FOWT), particularly the different substructure concepts. Then essentials of optimization, more specifically, the basics of Genetic Algorithm (GA) are also highlighted. Earlier research work dealing with FOWT design optimization, mainly with respect to the substructure, are reviewed as well. Following the study of [3], an optimization framework based on two structurally different GA, especially developed for the design optimization of the UBB, is described. Then main aspects of this particular cylindrical buoyancy body are presented, before highlighting the different stages of the optimization process. The final sections include the preliminary results for a given study case, as well as the conclusion and recommendations for future work to enhance the optimization framework presented here.

\subsection{Floating Foundations for Offshore Wind Turbines}

A FOWT is composed of three main components: the platform, the wind turbine and the mooring system. Floating platform configurations vary widely and it is important to adopt the correct classification as design aspects differ with the substructure type. The classification of floating platforms have its origin from the oil and gas industry, whose designs were adapted to meet the needs of the floating offshore wind industry. Floating substructures are classified based on the physical principle used to achieve static stability. With regards to floating offshore wind, there are three main stabilizing principles that are commonly mentioned in the literature and which can be gathered in a so called stability triangle presented in Figure 1, and were originally discussed in [4]:

- Ballast stabilized substructures have their center of gravity below their center of buoyancy and achieve stability with ballast weights hung below leading to a righting moment, which counteracts rotational displacements and stabilizes the system [4,5].

- Mooring stabilized platforms achieve stability through the use of mooring line tension, which generates the restoring moment when the structure is inclined [5].

- Buoyancy stabilized structures achieve stability through the use of the substructure's distributed buoyancy [4]. The water-plane area creates a stabilizing righting moment in case of rotational displacement of the floater [5].

Buoyancy stabilized

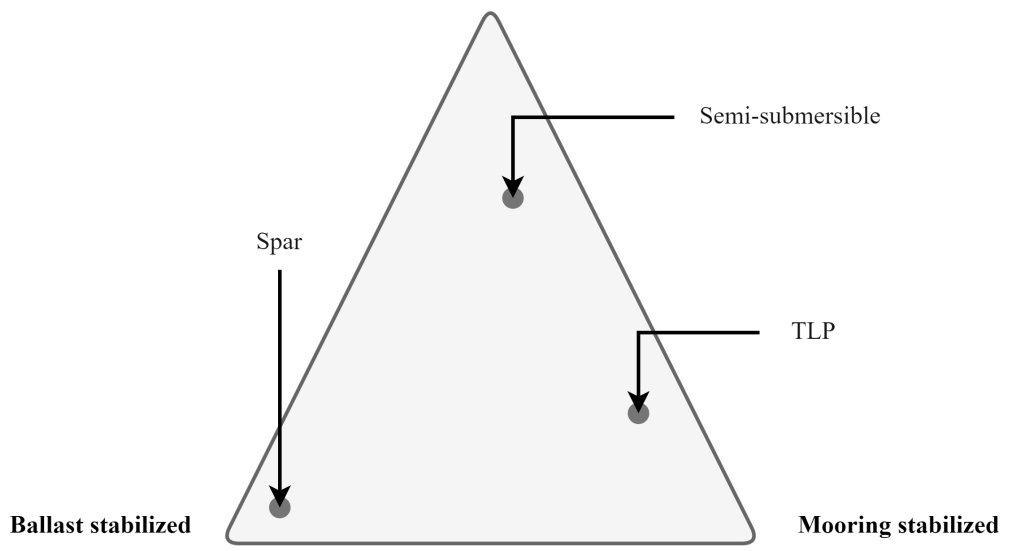

Figure 1. The different stabilising mechanisms of floating foundations for offshore wind turbines, adapted from [4].

Floating foundation concepts with different structural designs have been extensively proposed and studied in the literature, both in the academic and industrial field. In [2,6], a review of the floating offshore wind market is presented. Many different floating substructures concepts and demonstrator are outlined and their development over time is highlighted: from Statoil ${ }^{\circledR \prime}$ s milestone Hywind project, the first full-scale FOWT in 2011, to the WindFloat ${ }^{\circledR}$ floating offshore wind parks planned off the Portuguese and Scottish 
coast in 2018. FOWT substructures are usually classified into three different categories which use more or less a combination of the stabilizing principles shown in Figure 1:

- Semi-submersible and barge platforms are buoyant substructures which float at the surface of the sea while anchored to the seabed with catenary mooring lines.

- Spar floaters are long vertical and cylindrical structures with a large draft fixed to the seabed with mooring lines, transported horizontally and ballasted usually with concrete or seawater.

- Tension Leg Platforms (TLP) are semi-submerged and anchored to the seabed with taut mooring lines.

Currently, the major part of floating offshore wind projects presents semi-submersible or TLP substructures that are mainly made out of steel, for installation and cost efficiency purposes, taking advantage of the fixed offshore wind industry experience [2]. The structural design of floating foundation is usually strongly orientated towards ship structure design with stiffeners that are welded to the structural components to ensure stability and enough structural strength. Different substructure concepts and modular components have been developed with the aim of reducing the production cost by serializing the fabrication procedure [7]. Concrete is now also often used as primary material for the fabrication of floating foundations as it is cheaper than steel [2]. The design of floating platforms is now, and should, be optimized considering manufacturing aspects as well as other factors to reach an optimized design in terms of structural strength and cost efficiency. Particular examples already exist, such as the GICON ${ }^{\circledR}$-TLP on which this study focuses on and is described in Section 2.1, or the Eolink ${ }^{\circledR}$ floating foundation for which the design itself has been optimized for industrialization, rapid deployment and easy maintenance. Another interesting example is the Stiesdal ${ }^{\circledR}$ Tetra spar concept that offers a modular and industrialized substructure with components available in the current wind energy supply chain [8].

\subsection{Floating Offshore Wind Turbines Design Optimization}

The design of FOWT relies on the correct understanding of the behavior of the floating system and the grasping of the different physical phenomena that are at stake. The dynamic analysis of the system is unsurprisingly a difficult task, due to the harsh offshore environment it is exposed to and to the coupling effects of the different loads it is subject to. In addition, a FOWT is composed of many different components, and the behavior of the complete system is complicated by the coupled interactions of these components, therefore, the design of the whole system is a challenging task [4]. The design of marine structures is not a new topic as many research works have been carried out particularly in ship, oil and gas, and more recently in the fixed offshore wind industry. The design of floating substructures takes advantage of this previous knowledge and was first done using insights from these industries. Floating offshore wind early projects aimed at demonstrating the feasibility of the concept, whereas modern ongoing projects tend to focus on finding optimal design on an overall system level but also on a components level.

Floating offshore systems are complex and optimization can concern many topics, such as the blades of the rotor, the tower, the foundations or the mooring system, to name a few. Design optimization work on FOWT can have different goals, such as the cost of the system or its performances. When dealing with floating offshore wind, optimization work faces different specific challenges as FOWT are exposed to a harsh environment, leading to different types of loads with sometimes non-linear effects complexifying the analysis [9]. This has to be taken into account because, for optimization work, proper balance between accuracy and computational efficiency needs to be found. Complex analysis with few assumptions will lead to slow optimization analysis but with potentially more accurate results, as quick analysis using more simple models will be easier to repeat for optimization but will sometimes omit some important aspects of the modeling.

In the literature, many studies have been performed on the design optimization of the different components of floating offshore wind systems. Early research work with regards 
to floating offshore systems used parametric studies in order to screen different design possibilities such as in [10], where simplified frequency-domain analyses is performed to evaluate mainly TLP designs. Later work also performed parametric studies, like in [11], where fully coupled time-domain simulations are performed, or in [12], where a parametric study of cylinder-shaped floating platforms considering both concrete and seawater ballasted cylinder with different combination of draft is conveyed.

One of the first optimization tools developed for floating offshore wind, named Windopt, is presented in [13]. The tool is dedicated to spar type platforms and allows for an integrated design optimization of the foundations as well as the mooring system and dynamic power cable using a gradient-based method with the objective to minimize the cost of the whole system.

Another framework for floating support structure design optimization is described in [14]. It consists of, first, a geometric parametrization scheme that allows to span a wide design space covering the three main floater concepts already mentioned before: spar, TLP and semi-submersible type platform. In addition, the mooring system is also taken in consideration as it varies with the platform's geometry and the water depth. The performance of a given candidate is evaluated using a frequency domain analysis and the optimization process is conveyed using a particular GA, namely, the Cumulative MultiNiching Genetic Algorithm (CMNGA), capable of identifying multiple non-global optima in the design space. Later in [15], a hydrodynamic-based optimization process for floating support structures is presented. Instead of considering the design space in a conventional geometric way, it is represented by a linear combination of the hydrodynamic performances of a diverse set of basis platform geometries. Similar work can be found in [16], where a multi-objective design optimization work is presented. Improvements regarding the modeling of the system is brought by using a coupled approach in the frequency domain and a Kriging-Bat optimization method, another evolutionary algorithm.

Recently, a fully integrated design optimization framework for spar type floater is developed and presented in [17]. Another GA is used, namely, the Non dominated Sorting Genetic Algorithm II (NSGAII), as well as other evolutionary algorithms that are useful when dealing with multi-objective optimization problems. A framework for conceptual design optimization of floating platform is presented by [18]. This time the optimization process uses a gradient based method namely the sequential quadratic programming method. The objective functions are here again the cost of the system calculated based on its geometric characteristics.

Some examples of optimization work regarding other components of a floating offshore wind energy system can be found in [19], where the hydrostatic preliminary design of dynamic inter-array cables is performed through a parametric study where water depth and cable length are varied. In [20], a framework for multi-objective optimization of the mooring systems is done using a surrogate model coupled to the NSGAII in order to minimize both the cost and cumulative fatigue damage of the mooring system.

With the goal to improve the model floating offshore system, ref. [21] conducted an parametric integrated optimization study where the semi-submersible substructure as well as the wind turbine controller are optimized, with the objective to minimize cost and response to wind and wave excitation. The floating system is modeled using the Simplified Low Order Wind Turbine (SLOW) model developed in the thesis work [22].

As the floating platform is one of the most relevant components in terms of cost, design optimization studies are often focused on the the substructure, as it is an area which shows potential for cost reduction [9]. It is also the case of the optimization work presented in this study, which focuses on the buoyancy body of floating substructures. A complete and more detailed review work with regards to the design optimization of floating offshore foundation can be found in $[9,23]$.

The complete state of the art on design optimization of FOWT is not performed here, as only some of the research work was reviewed. It is important to highlight the European project LIFES 50+, which ended in 2019 and dealt with efficient substructure design for 
very large FOWT. The objectives of the projects were successfully achieved by delivering two optimized floating foundations designed for $10 \mathrm{MW}$ turbines through numerical and experimental validation, as well as qualitative deliverable regarding the efficient design of floating substructures.

\subsection{Optimization with Genetic Algorithm}

As seen in the previous section, many optimization work dealing with FOWT were previously performed. With computational power getting more and more efficient, manual iteration for optimization is now replaced by computer-aided optimization using different algorithms and techniques. The book [24] provides a detailed theoretical background for optimization, particularly for engineering design optimization, where any numerical methods, optimization techniques and algorithms are covered. Only basic knowledge on optimization and GA are highlighted here.

Every design optimization work requires a clear definition of the mathematical problem that is wished to be solved. The design variables are a finite set of one or more variables characterizing the system to be optimized and remained fixed during one iteration of the optimization process. These variables are chosen between the lower and upper bounds of the design space, which is defined and fixed before the optimization process starts. In order to evaluate a given design, defined by its design variables, objective functions (sometimes called fitness functions) need to be defined in order to quantify the "fitness" of the given design. It is important to notice that sometimes more than one objective function is used defining a multi-objective optimization problem. The so-called Pareto front can then be establish and used to evaluate the trade off between different objectives. The objective functions can either be minimized or maximized depending on the goal of the optimization. Most commonly, optimization problems are defined to minimize objective functions. This does not prevent from maximizing a given function by reformulating the problem as finding the minimum of the opposite of the given function. Defining the objective functions is not always an easy task and is often the key in establishing properly an optimization problem. Many design optimization problems require the definition of constraints, which are functions of the design variables. Usually, equality and inequality constraints are defined distinctly, and the set of designs that satisfy all constraints is usually called the feasible region.

To summarize, for an optimization problem with $n_{x}$ design variables, $n_{f}$ objective functions, $n_{g}$ inequality constraints and $n_{h}$ equality constraints, the general mathematical optimization problem can be written as in [24]:

$$
\begin{array}{lll}
\operatorname{minimize} & f_{i}(x), & i \in \llbracket 1 ; n_{f} \rrbracket, \\
\text { subject to } & x_{j}^{L} \leq x_{j} \leq x_{j}^{U}, & j \in \llbracket 1 ; n_{x} \rrbracket, \\
& g_{k}(x) \leq 0, & k \in \llbracket 1 ; n_{g} \rrbracket, \\
& h_{l}(x)=0, & l \in \llbracket 1 ; n_{h} \rrbracket,
\end{array}
$$

where $x$ is the design variables vector, the superscripts ${ }^{L}$ and ${ }^{U}$ respectively denote the lower and upper limit for a given design variable, $f_{i}$ is one of the objective functions, $g_{j}$ is one of the inequality constraints and $h_{k}$ is one of the equality constraints.

As seen in the optimization work reviewed in the previous section, evolutionary algorithm such as GA are often used when dealing with FOWT design optimization. GA are part of evolutionary algorithms which are inspired by biological evolution process. These algorithms are population-based, meaning they make the use of multiple individuals during the search process through the design space. During the optimization process the population evolves over generations using three main steps:

- Selection is based on natural selection, where more favorable individuals of the population survive longer and are kept within the population.

- Crossover, inspired by chromosomal crossover, is the exchange of genetic material between two individuals, the parents, resulting in one or more offspring. 
- Mutation mimics the genetic mutation phenomenon, where a change in the gene sequence of an individual occurs randomly.

Most GA follow the general procedure shown in Figure 2. First, an initial population constituted of a given number of individuals is defined. Then, with every generation, the population evolves through selection, crossover and mutation operations, leading to a new population with new individuals. The selection and crossover operations promotes the creation of fitter individuals, whereas the mutation operation ensures that a certain diversity within the population is kept. After a given stopping criteria (convergence or maximum generation reached), the population stops evolving leading to the final population which present within its individuals the fittest individual, the solution to the optimization problem. Even if GA are similar in their structure, there is a lot of flexibility in how and when the genetic operations are performed, leading to many type of genetic operators and many different algorithms. A detailed classification and description of GA and genetic operators can be found in [24].

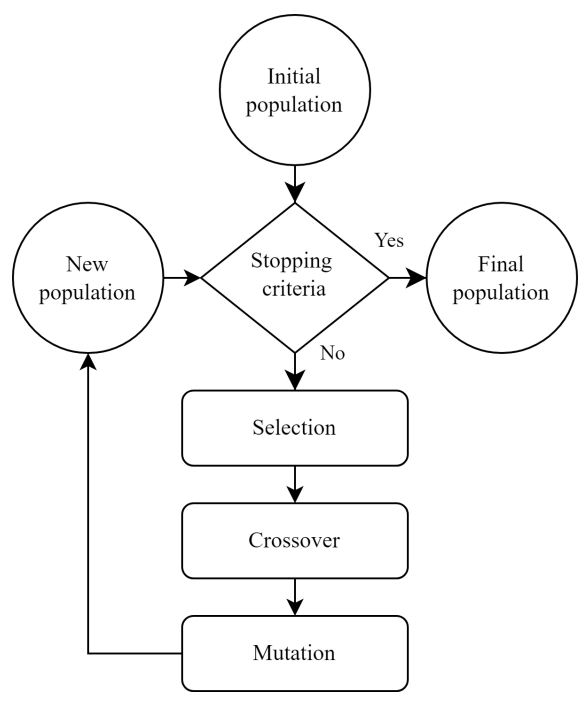

Figure 2. Scheme of the general structure of genetic algorithms.

\section{The Universal Buoyancy Body}

In the previous study [3], the so called UBB is developed and presented. This particular cylindrical buoyancy body was thought and developed as a modular components in order to be integrated in different floating substructure type, and with a relatively simple manufacturing process. This previous study focuses on its description and structural design for which the structure's strength and fatigue resistance is analyzed. Further on, the manufacturing process of the buoyancy body is outlined and the economic efficiency as well as the structural capabilities of its design are exemplified. In this section, the main aspects of this particular buoyancy body are summarized in order to introduce and better understand the optimization process which is presented later in Section 3.

\subsection{The GICON ${ }^{\circledR}-T L P$}

In 2009, the GICON ${ }^{\circledR}$ group and their partners started a research project regarding a floating platform for offshore wind turbines, eventually leading to the evolving design of the so called GICON ${ }^{\circledR}$-TLP. The latest design of this TLP consists of a steel and concrete substructure with four buoyancy bodies that are arranged in a rectangle shape, connected to each other by horizontal bracing tubes and to the wind turbine transition piece by vertical and diagonal tubes. An illustration of the GICON ${ }^{\circledR}$-TLP's latest design is shown in Figure 3, as well as the previous designs since its first concept. Previous studies such as $[25,26]$ describe the development path of this TLP and the major design modifications it has undergone. 


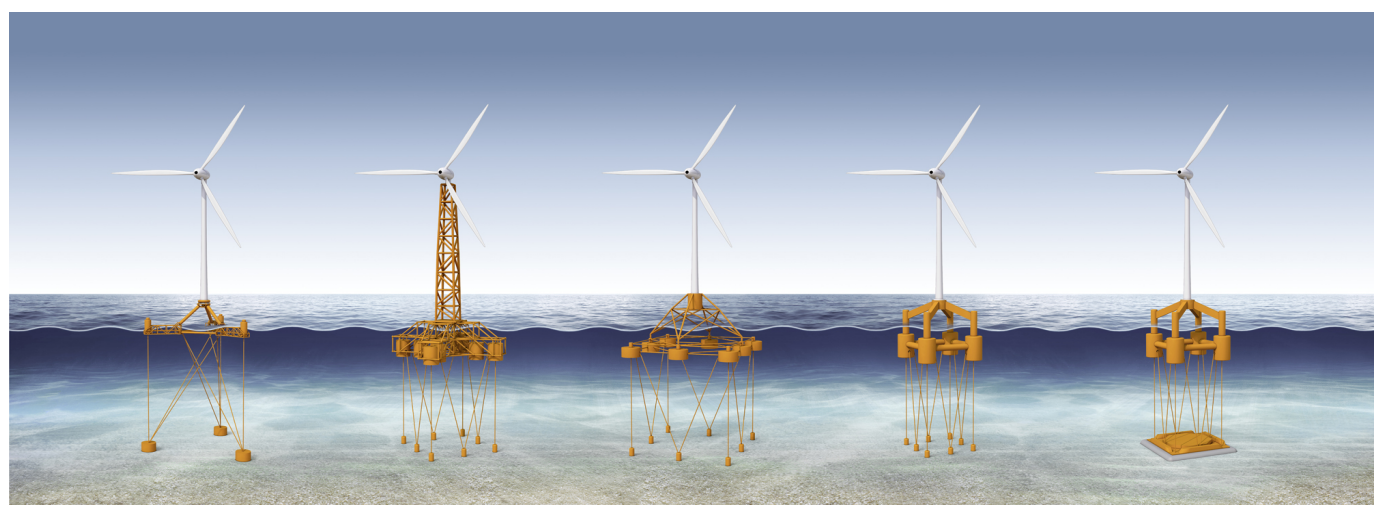

Figure 3. The development path of the GICON ${ }^{\circledR}-\mathrm{TLP}$, from [7].

\subsection{The Universal Buoyancy Body Structural Design}

The majority of current floating substructure designs involve buoyancy bodies in their configuration, which have similarities particularly for TLP and semi-submersible platforms. Many floater concepts presents cylindrical buoyancy bodies, like the GICON ${ }^{\circledR}$-TLP, which nowadays includes four cylindrical shaped buoyancy bodies in its design. In order to reduce costs, a buoyancy body could be scaled in a wide range and be integrated as a standardized component in the primary structure of floating wind turbine foundations. The design of floating substructure components is usually similar to classical ship structures design. The fabrication process takes place at yard and requires large number of stiffeners and welds to ensure structural strength and stability of the structure. This approach leads in the end to high manufacturing time and costs, and therefore to higher LCoE.

With the development of the GICON ${ }^{\circledR}$-TLP substructure globally aiming to reduce cost of floating offshore wind, a particular buoyancy body design was proposed in [3]. The UBB is characterized by a simple design, inspired by wind turbine tower and monopile designs. The UBB consists of four main components such as an inner and outer pipe as well as an upper and lower cover, shown in Figure 4. The pipes are made out of thick steel sheets with a similar fabrication process as for monopiles, and provides a sufficient stiffness without the use of classical ship's design stiffeners. The covers also provide stiffness to the structure with a steel/concrete/steel "sandwich" type design at the top and bottom on the pipes. The details of the covers' structure are also shown in Figure 4. This particular buoyancy body is at the core of the optimization work that is presented later in this study. Figure 5 shows a 3D view of the UBB with both variants for the geometry of its covers: flat and conical shaped covers.

The UBB can be integrated into the surrounding substructure of a given floater at the top and at the bottom of the inner pipe by specific connector, without altering the given structural characteristics of the floating platform. This particular structural design globally enables a relatively fast manufacturing process while keeping a certain level of structural efficiency. On one hand, the structural mass of the buoyancy bodies increases and therefore the material costs also increase, while, on the other hand, manufacturing time and total cost drop. Another advantage of the UBB is that its design can be adapted for future and already existing floating substructure concepts regardless of their type, as many different floating platforms include cylindrical buoyancy bodies in their structural design. Eventually, the UBB could be manufactured in dedicated facilities in relatively high quantity according to different substructure types, standards, offshore sites or any other criteria relative to the manufacturer or project developer. A complete presentation of the UBB design and analysis can be found in [3]. 


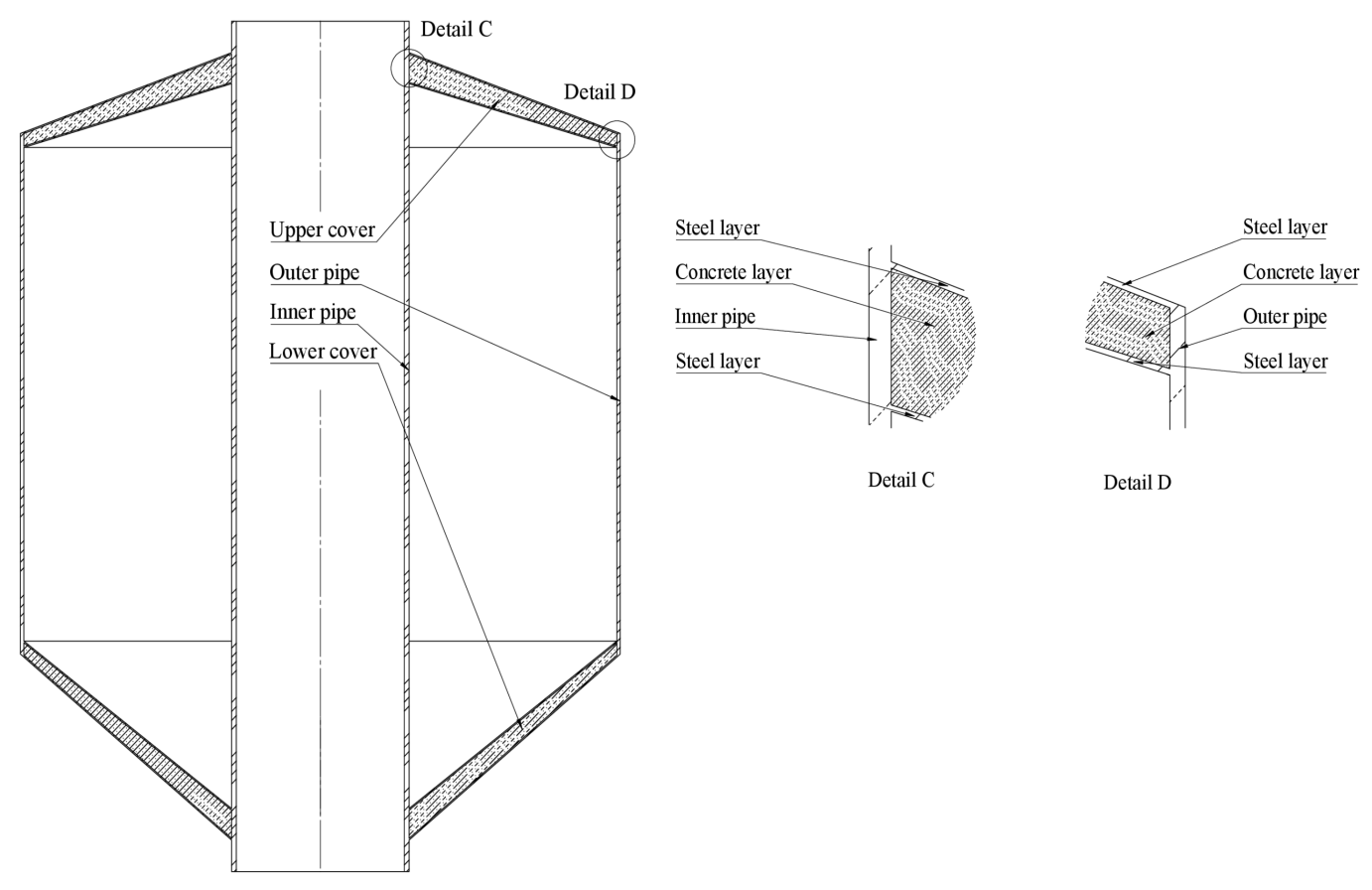

Figure 4. Technical drawing of the Universal Buoyancy Body in sectional view, the whole body on the left and details of the covers on the right, adapted from [3].
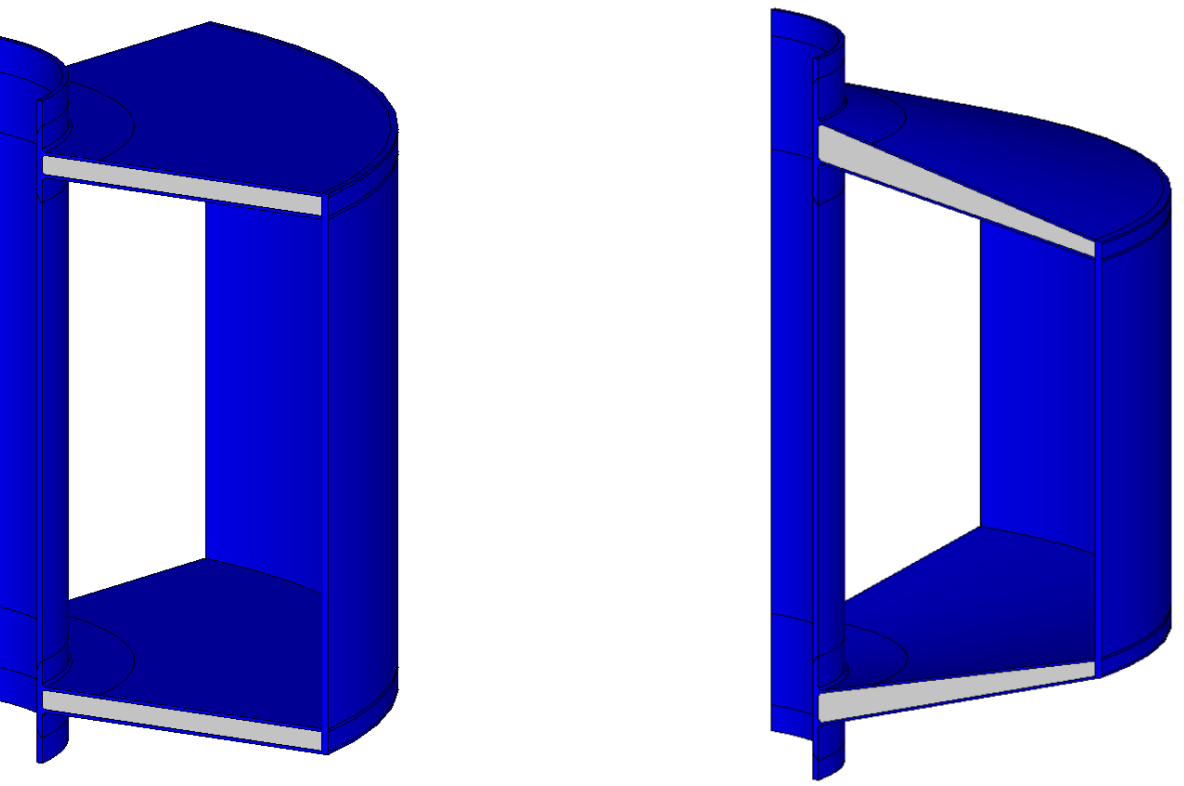

Figure 5. A 3D view of the Universal Buoyancy Body with flat covers on the left, and conical shaped covers on the right.

\section{Design Optimization Process}

This section presents the design optimization process for the UBB described in the previous section. The optimization framework is detailed including the parametrization scheme for the UBB geometry, the model for the structural analysis performed, the objective and constraints considered for the optimization, as well as the optimization algorithms used in this study. 


\subsection{Parametrization Scheme}

A set of design variables that describe the UBB geometry is needed before undertaking any optimization task. Due to symmetry considerations for cylindrical buoyancy bodies, only half of the UBB geometry is parametrized. For this optimization work, design variables are real values and defined as follows: $L$ the is cylinder length, $d_{i}$ and $d_{o}$ are respectively the inner and outer pipe diameters, $t_{i}$ and $t_{o}$ are respectively the inner and outer pipe thicknesses, and $t_{c}$ and $t_{s}$ are respectively the concrete and steel thicknesses of the covers. As the upper and lower covers can be executed in a flat or a conical shape, design variables include $\alpha$, the angle at the covers. As it is structurally interesting that the thickness of the concrete layer in the covers increases towards the inner pipe of the UBB, an expansion coefficients $C_{\text {exp }}$ is therefore considered. Finally, the complete set of design variables is defined as:

$$
x=\left[L, d_{i}, d_{o}, t_{i}, t_{0}, \alpha^{t o p}, \alpha^{b o t}, C_{\text {exp }}^{t o p}, C_{\text {exp }}^{\text {bot }}, t_{c}^{\text {top }}, t_{c}^{b o t}, t_{s}^{\text {top }}, t_{s}^{b o t}\right]
$$

The design variables for the covers are doubled and denoted with a superscript top and ${ }^{b o t}$ respectively for the top and bottom covers. The complete parametrization of the UBB geometry and the representation of the design variables are shown in Figure 6.

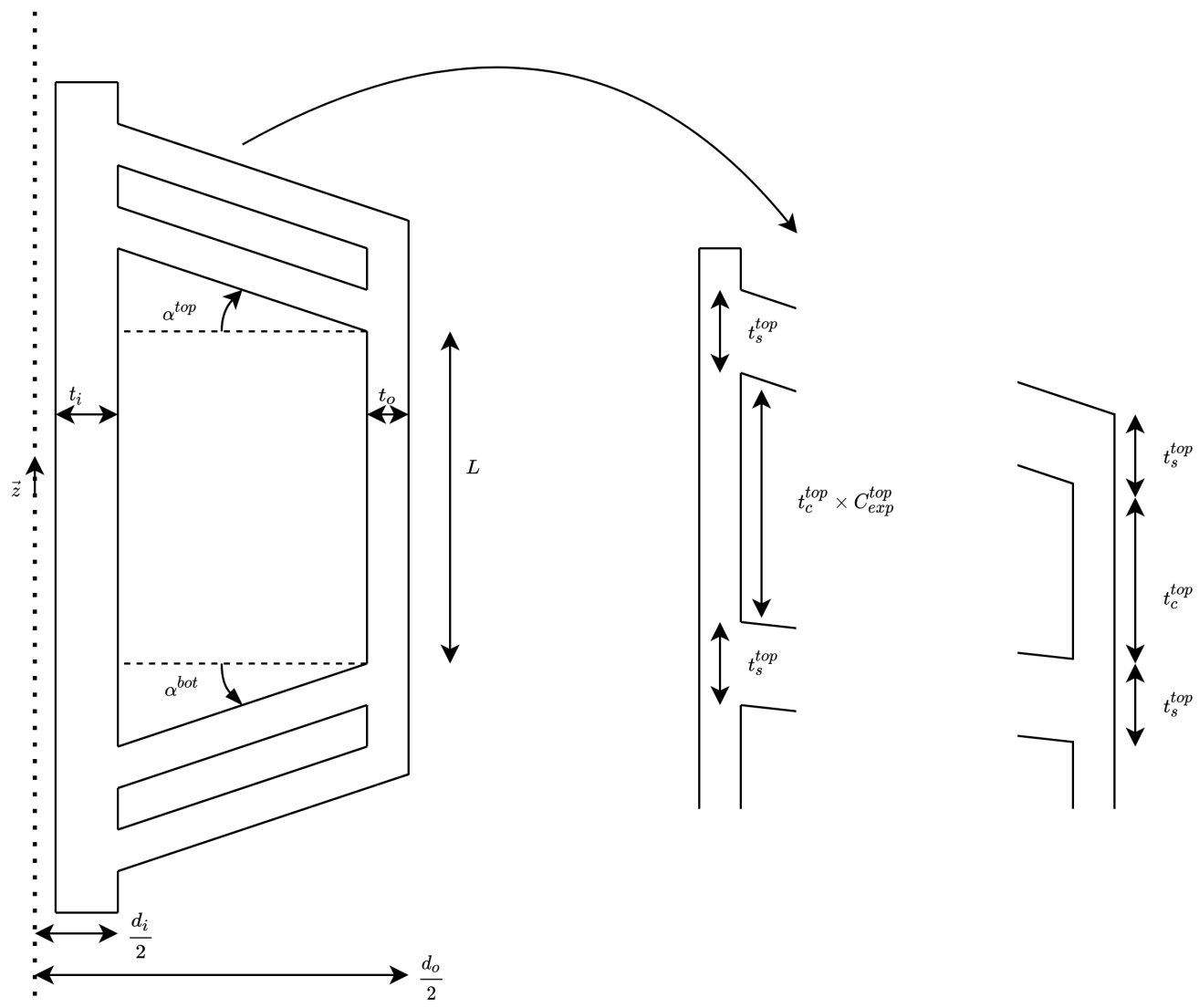

Figure 6. Parametrization of the UBB geometry and illustration of the design variables, for the whole body on the left and details of the covers on the right.

\subsection{Structural Analysis}

To perform the structural analysis of a given UBB design, and verify its strength, the Finite Element Analysis (FEA) tool Ansys ${ }^{\circledR}$ is used. Similarly as in [3], a global model is created as a $0.1^{\circ}$ section of the UBB with adequate symmetrical boundary conditions at the cutting areas $\left(u_{\theta}\right.$, rot $_{r}$ and rot $_{z}$ are locked to zero in global cylindrical coordinate system). Ansys ${ }^{\circledR}$ SOLID186, 3D high order 20 nodes solid element is used for meshing the geometry 
as they are well suited for hexahedron elements and to model irregular meshes [27]. The model of the UBB implemented in Ansys ${ }^{\circledR}$ Mechanical is shown in Figure 7 as well as the mesh used for the study. The connection of the upper end of the inner pipe to the surrounding floater structure is modeled as a boundary condition with translational degrees of freedom locked in all three directions $\left(u_{r}, u_{\theta}\right.$ and $u_{z}$ are locked to zero in global cylindrical coordinate system). This study focuses mainly on the GICON ${ }^{\circledR}$-TLP and wave loads have a minor effect on the buoyancy body's structure and can be neglected. Therefore, the relevant design loads implemented in the model are tendon rope loads and hydrostatic water pressure loads, as shown in Figure 7. Rope loads are applied at the bottom of the inner pipe as nodal forces (red arrows) and hydrostatic pressure are applied as pressure with height gradient at the outer surface of the UBB (multi-colored arrows).

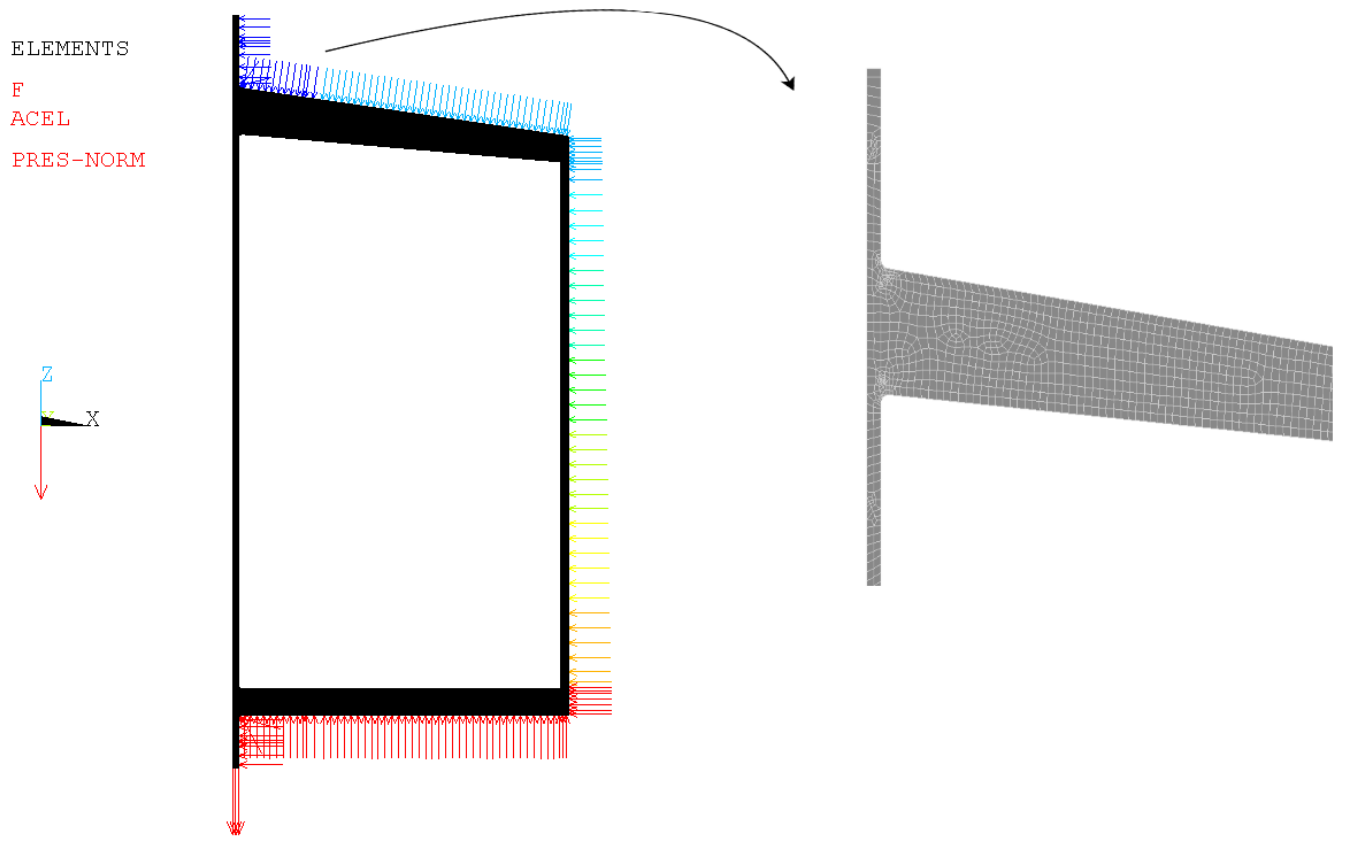

Figure 7. Model of the UBB implemented in Ansys ${ }^{\circledR}$ Mechanical, with boundary conditions on the left and part of the mesh (covers) on the right.

As concrete and steel are the two main materials used in the fabrication process of the UBB, Table 1 summarizes these materials main physical properties used in the present study, particularly the values implemented in Ansys ${ }^{\circledR}$ for the structural analysis.

Table 1. Main physical properties of the materials implemented in Ansys ${ }^{\circledR}$ Mechanical.

\begin{tabular}{lccc}
\hline Material & Density $\left(\mathbf{k g . m ^ { - 3 }}\right)$ & Young's Modulus (GPa) & Major Poisson's Ratio \\
\hline Steel & 7850 & 210 & 0.3 \\
Concrete & 2400 & 35 & 0.2 \\
\hline
\end{tabular}

\subsection{Objective and Constraints}

The overall goal of the optimization work presented here is to obtain a given design for the UBB which offers the lowest cost possible. Consequently, a cost model is needed in order to define the cost of a potential UBB design based on a given set of design variables. The work performed here is therefore a single objective optimization. The cost model used in this study is relatively simple as only the total material and manufacturing cost are consider to compute the overall cost of a given UBB design.

Experience values for the GICON ${ }^{\circledR}$-TLP show that these costs at yard for typical ship structure oriented floating substructures are up to $4.5 \mathrm{k} € . \mathrm{t}^{-1}$. The experience values 
for monopile in series manufacturing costs are usually up to $2 \mathrm{k} € \cdot \mathrm{t}^{-1}$ [3]. For concrete, the material and processing costs are roughly assumed to be up to $0.3 \mathrm{k} € . \mathrm{t}^{-1}$. In our case here, the steel unit cost used is consider similar as the one for monopile production because the design and manufacturing process of the UBB is derived from the monopile industry. Table 2 summarizes the values of the different cost used for the presented work.

Table 2. Manufacturing costs including material costs implemented for the cost model.

\begin{tabular}{lcc}
\hline Notation & Unit Cost $\left(\mathbf{k} \in \mathbf{t}^{-\mathbf{1}}\right)$ & Description \\
\hline$C u_{\text {sub }}$ & $3.5-4.5$ & $\begin{array}{c}\text { Ship oriented substructure } \\
\text { manufacturing cost }\end{array}$ \\
$C u_{\text {mono }}$ & $1.5-2$ & Monopile in series manufacturing cost \\
$C u_{\text {steel }}$ & 2 & Steel manufacturing cost considered \\
$C u_{\text {concrete }}$ & 0.3 & Concrete manufacturing cost considered \\
\hline
\end{tabular}

Eventually the objective function $f$ to minimize and used for optimization can be computed as:

$$
f(x)=M_{\text {steel }}(x) \times C u_{\text {steel }}+M_{\text {concrete }}(x) \times C u_{\text {concrete }},
$$

where $x$ is the set of design variables defined previously, $M_{\text {steel }}$ and $M_{\text {concrete }}$ are respectively the steel and concrete total mass, and $C u_{\text {steel }}$ and $C u_{\text {concrete }}$ are respectively the steel and concrete unit cost mentioned above. The UBB is designed in order to provide a certain buoyancy force according to the the type of floater, standards or the environment of the offshore wind project. It should do so, while making sure that the strength of the structure is insured. For this matter, two inequality constraints $g_{1}$ and $g_{2}$ or considered and defined as:

$$
\begin{aligned}
& g_{1}(x) \geq F_{\text {buoy }}^{\text {min }} \\
& g_{2}(x) \leq \sigma_{\text {max }}
\end{aligned}
$$

where $x$ is the set of design variables defined previously, $F_{b u o y}^{\min }$ the minimum required buoyancy force and $\sigma_{\max }$ the maximum occurring stress allowed in the UBB structure. The buoyancy force of the UBB is computed as:

$$
F_{\text {buoy }}(x)=\left(\rho_{\text {water }} V_{\text {disp }}-\rho_{\text {steel }} M_{\text {steel }}(x)-\rho_{\text {concrete }} M_{\text {concrete }}(x)\right) g,
$$

where $V_{\text {disp }}$ is the displaced volume of sea water due to the UBB, $\rho_{\text {water }}, \rho_{\text {steel }}, \rho_{\text {concrete }}$ are respectively the sea water, steel and concrete density and $g$ the gravity. The stress distribution in the global structure is obtained after the structural analysis performed using Ansys ${ }^{\circledR}$ Mechanical. After some postprocessing operations, the maximum nodal stress can be obtained and checked against $\sigma_{\max }$. In this study the equivalent Von Mises stress (SEQV) is used as it is often chosen for yield checking, and values for steel for example, can be obtained from offshore design standards such as [28-30].

\subsection{A Basic Genetic Algorithm}

As seen in Section 1.2, GA are often used when dealing with FOWT design optimization because of the system's complex behaviour and, therefore, the complex formulation of the objective functions and constraints. In the present study, the formulation of the objective function is relatively simple and straightforward; however, the stress constraints ensuring the UBB strength requires an FEA, which needs some computational effort.

To carry out the design optimization of the UBB, a basic GA is implemented and follows the basic scheme shown in Figure 2. The selection operation is performed using Tournament Selection (TS), as this method is more efficient and prevents the problem of premature convergence to local optima, when compared to other selection techniques 
such as Roulette Wheel Selection (RWS) [31]. In the TS operation, a certain number of individuals are randomly chosen from the population to compete, often called a "pool" of individuals, and the one individual with the best fitness is selected. The crossover operation is performed using the Simulated Binary Crossover (SBC) method, that is particularly adapted for real valued optimization problems and continuous design spaces [32], which is the case here. For this operation, two parents are considered from the selection operation performed previously, and produces two offsprings following the rule below:

$$
\left\{\begin{array}{l}
x_{1}^{o}=\frac{(1+\beta) x_{1}^{p}+(1-\beta) x_{2}^{p}}{2} \\
x_{2}^{o}=\frac{(1-\beta) x_{1}^{p}+(1+\beta) x_{2}^{p}}{2},
\end{array}\right.
$$

with $x_{1}^{p}, x_{2}^{p}$ being the design variables of the parents, and $x_{1}^{o}, x_{2}^{o}$ being the design variables the produced offsprings, and:

$$
\beta= \begin{cases}2 u^{\frac{1}{\eta_{c}+1}} & \text { if } u \leq \frac{1}{2} \\ \frac{1}{2(1-u)} & \text { otherwise. }\end{cases}
$$

where $u \in[0,1]$ and $\eta_{c}$ denotes the distribution index, which allows a tuning of the crossover operation. Large value of this index tends to generate offsprings closer to the parents as smaller index allows the offsprings to be far from the parents. The mutation operation is performed using random mutation, generating a mutant with random design variables chosen uniformly within the entire design space. Both the crossover and mutation operations are performed with their own probability of happening, respectively called crossover and mutation rate. Table 3 summarizes the description of the basic GA main parameters implemented in this optimization work.

Table 3. The basic GA main parameters and their descriptions.

\begin{tabular}{lc}
\hline Parameter & Description \\
\hline$n_{\text {pop }}$ & Size of the population \\
$n_{\text {gen }}$ & Maximum number of generation \\
$n_{\text {parents }}$ & Number of parents to be selected \\
$n_{\text {pool }}$ & Size of the pool to be consider for TS operation \\
$\eta_{C}$ & Distribution index for the SBC operation \\
$r_{\text {crossover }}$ & Crossover rate \\
$r_{\text {mutation }}$ & Mutation rate \\
\hline
\end{tabular}

\subsection{The Cumulative Multi-Niching Genetic Algorithm}

In [33], a particular GA which makes use of niching techniques, namely, the CMNGA, is developed and presented. A complete description of this algorithm and the techniques developed are provided, whereas, here, only the key features are highlighted.

The main characteristic of the CMNGA is that it is able to deal with multi-modal objective functions and identify multiple local optima within the design space. Like other GA, it applies the different genetic operators described in Section 1.3 with some modifications. The structure of the CMNGA is shown in Figure 8.

A proximity-weighted scaling process is performed on the objective function to provide an equitable treatment of all significant local optima. Local optima are identify and selected if they are fitter than all of their nearest neighbors, and an equal scaled fitness value is then computed for each one of them. This scaled objective function is 
afterward used throughout the rest of the optimization process during the crossover and mutation operations.

For the CMNGA, the selection operation is slightly different compared to other classical GA. For every parent couple, one of the parents is selected using a fitness proportionate selection method such as RWS. The second parent is then chosen from a pool of individuals which are themselves selected using a distance proportionate selection method. The closer an individual is from the first parent, the more chance he has to be selected to be in the pool. The fittest individual of the pool is then selected as the second parent for the crossover operation. The crossover and mutation operations implemented are the same as the one mentioned earlier in Section 3.4, namely, the SBC and random mutation method. Table 4 summarizes the description of the CMNGA main parameters.

Another particular feature of the CMNGA is that its population extends over the generation and the genetic operations, whereas classical GA have a population that evolves with a fixed number of individuals. Potential offspring that are overly similar to existing individuals are not added to the population by use of an adaptive fitness related proximity constraint, which forces convergence around fitter regions of the design space leading to a sparse population density in less fit regions. This approach prevents an excessive number of objective function evaluation, which is often the case with other classical GA.

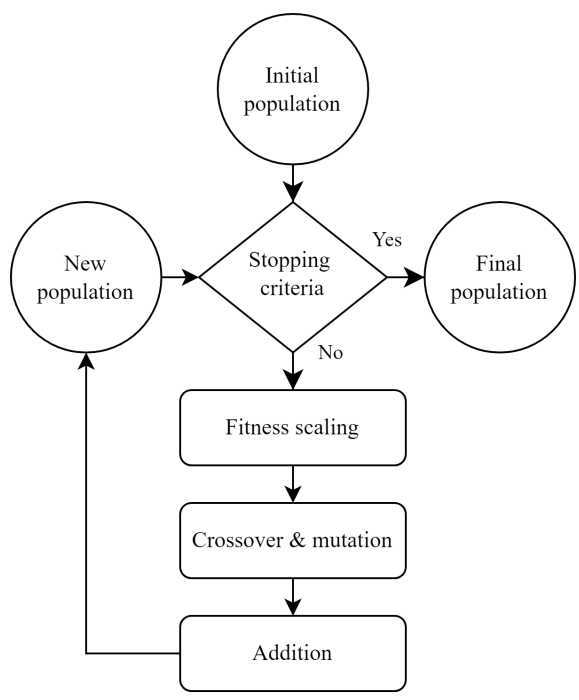

Figure 8. Scheme of the structure of the Cumulative Multi-Niching Genetic Algorithm.

Table 4. The CMNGA main parameters and their descriptions.

\begin{tabular}{lr}
\hline Parameter & Description \\
\hline$n_{\text {pop }}$ & $\begin{array}{l}\text { Size of the starting population } \\
n_{\text {max }} \\
n_{\text {gen }}\end{array}$ \\
$n_{\text {crossover }}$ & Maximum size of the population \\
$n_{\text {mutation }}$ & Maximum number of generation \\
$n_{\text {min }}$ & Number of individuals to be added to the population by crossover \\
$n_{\text {pool }}$ & Number of neighbors to identify potential local optimum \\
$\eta_{C}$ & Size of the pool to be consider for the selection method \\
\end{tabular}

The CMNGA is highlighted here because it has been used before for optimization work notably for FOWT design optimization already mentioned in Section 1.2, such as [14]. In addition, its implementation is well documented and seems well suited for the opti- 
mization problem presented here. Indeed, for the design optimization work presented here, the computation effort to obtain the objective and constraints function values for a given design of the UBB is non-negligible. The FEA performed for the structural analysis requires a simulation time of a couple of seconds and limiting the number of objective and constraints function evaluation lead in the end to computational time savings.

\subsection{Implementation Validation}

In order to validate the implementation of the algorithms discussed earlier, optimization is carried out using both GA on two particular test functions. In [34], many different test functions with diverse properties in terms of modality for optimization algorithms are reviewed. Two multi-variable (two-dimension) test functions, uni-modal $f_{1}$ and multimodal $f_{2}$, are chosen to verify the implementation of both GA:

$$
\left\{\begin{array}{l}
f_{1}(x, y)=-200 e^{\left(-0.002 \sqrt{x^{2}+y^{2}}\right)} \\
f_{2}(x, y)=\sin (x) e^{(1-\cos (y))^{2}}+\cos (y) e^{(1-\sin (x))^{2}}+(x-y)^{2},
\end{array}\right.
$$

Both GA showed relatively good results for both test functions when comparing their solutions to the baseline solution, validating the implementation of both algorithms. Table 5 summarizes the solutions obtained using both GA and the baseline solutions from [34]. In the case of multi-modal function, the CMNGA shows its ability to identify multiple optima, whereas the basic GA can only identify one of them.

The multi-modal $f_{2}$ function presents two local minima with the same function values, $f_{2}(4.701,3.153)=f_{2}(-1.582,-3.13) \simeq-106.7$. The basic GA solution for $f_{2}$ oscillates randomly between the two minima after every optimization run, while the CMNGA identifies both of them every run. The details of the optimization runs, and the algorithms' parameters used for the previous results are not shown here as they will be highlighted for the study case given in the next section.

Table 5. Test functions' solutions comparison.

\begin{tabular}{lcc}
\hline & Solution for $f_{1}$ & Solution for $f_{2}$ \\
\hline$[34]$ & $(0,0)$ & $(4.701,3.153)$ and $(-1.582,-3.13)$ \\
GA & $(0.076,0.022)$ & $(4.712,3.167)$ or $(1.554,3.119)$ \\
CMNGA & $(0.004,0.021)$ & $(4.713,3.146)$ and $(1.587,3.143)$ \\
\hline
\end{tabular}

\subsection{Optimization Framework}

In order to implement the design optimization process detailed above, the interpreted programming language Python is used. The use of Python's object-oriented programming language is motivated by the fact that codes are usually kept short, it is easy to read as well as to understand. In addition, Python is often used as a programming framework for engineering problems as it presents many different standard libraries that offer a variety of already implemented tools. Figure 9 gives an overview of the presented optimization process, highlighting its structure as well as the different files and modules which are at stake.

First, an input file (json format) is read at the very beginning of the optimization process. This allows to define the design space, the GA to be used for the optimization, its parameters and other parameters regarding Ansys ${ }^{\circledR}$ performances. The optimization code is then structured into two main modules.

The first one contains all the routines needed to run APDL commands or read APDL input files. Within this module, an Ansys ${ }^{\circledR}$ mechanical instance is started, and elements, materials and the UBB model are defined. This module also performs the FEA and some postprocessing operations in order, for example, to verify the stress constraint. The structural analysis performed with Ansys ${ }^{\circledR}$ mechanical is carried out using Ansys ${ }^{\circledR}$ Parametric 
Design Language (APDL) input files. The programming in Python allows the use of PyAnsys [35], a collection of packages that enable the use of Ansys ${ }^{\circledR}$ products. APDL commands can then be run directly through python, or entire APDL scripts can be read. In this study the Ansys ${ }^{\circledR}$ Student 2021 R2 version is used.

The second module consists of the routines needed for the optimizer implementation. The genetic operators such as crossover, mutation or the fitness scaling operation for the CMNGA are implemented there as well as other mathematical operations which are needed for both algorithms to perform well.

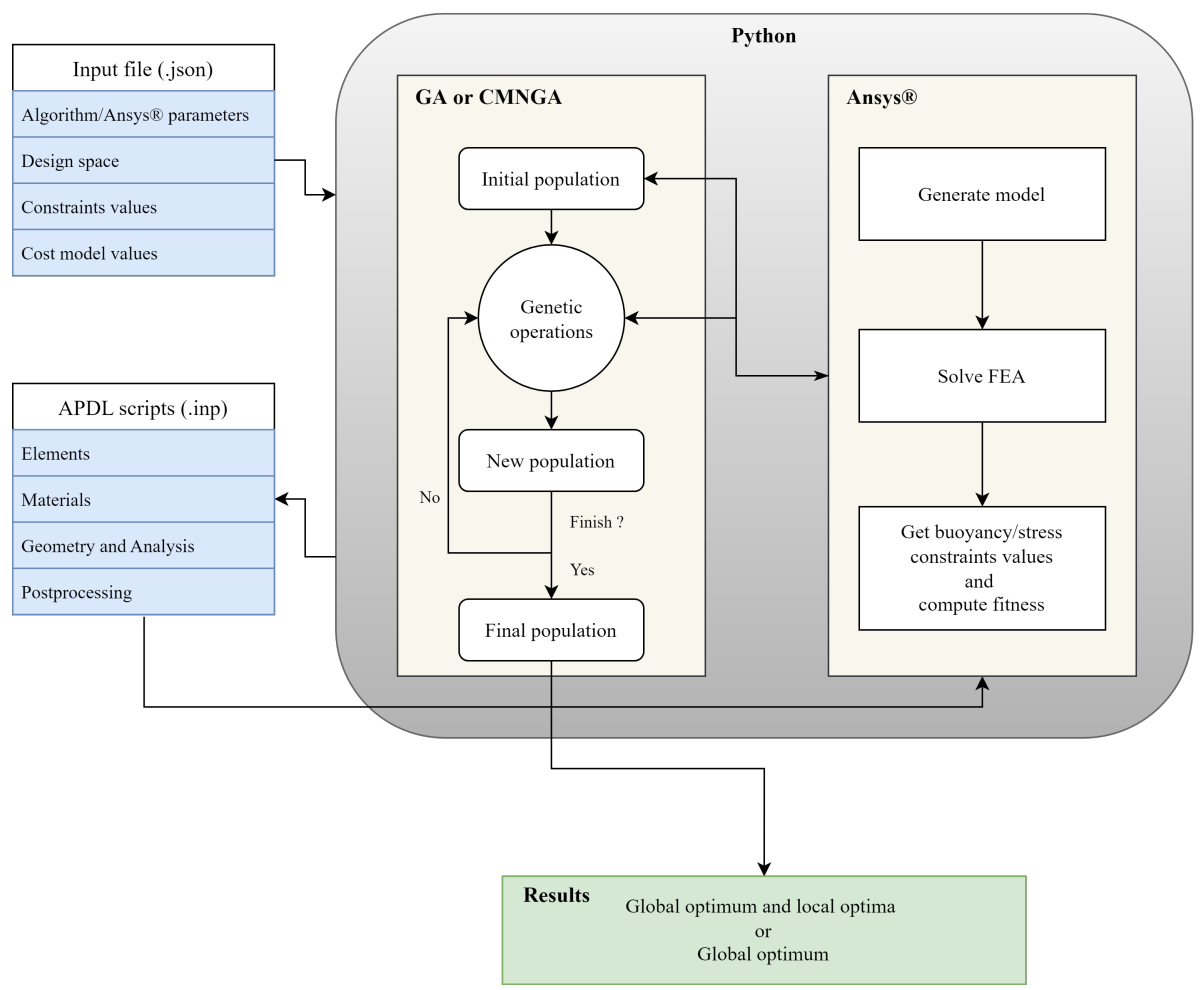

Figure 9. Framework of the Universal Buoyancy Body design optimization process.

\section{Preliminary Results}

This section presents the UBB design optimization results for a given study case using the optimization framework described previously in this work. First, the study case is introduced, then the results for both the CMNGA and the basic GA are presented.

\subsection{Study Case}

The given study case focuses on the design optimization of one UBB of the GICON ${ }^{\circledR}$ TLP. Geometrical dimensions of the UBB are usually ruled by manufacturing constraints and experience values. All of the inputs used for the present study case are summarized in Table 6. For confidential issues, some of the values used as inputs have been modified and are generic values still relevant for the optimization work presented here.

For the inner pipe the typical diameters are in the range of $2 \mathrm{~m}$ to $4 \mathrm{~m}$ with a sheet thickness between $20 \mathrm{~mm}$ and $150 \mathrm{~mm}$. Similarly, typical diameters for the outer pipe are in the range of $10 \mathrm{~m}$ to $15 \mathrm{~m}$ with a sheet thickness between $50 \mathrm{~mm}$ and $100 \mathrm{~mm}$. Regarding the UBB covers, the typical sheet thickness of the steel layers is between $10 \mathrm{~mm}$ to $40 \mathrm{~mm}$ while the concrete layer thickness will be typically between $150 \mathrm{~mm}$ and $500 \mathrm{~mm}$. The UBB length is considered to be between $8 \mathrm{~m}$ and $15 \mathrm{~m}$, which is a representative range of the length of other substructures' buoyancy bodies. The angles of the covers is set to not exceed $30^{\circ}$, as larger angles might lead to manufacture problems. The maximum expansion coefficient for the concrete layer of the covers is set to 3 . 
For the given study case, the UBB is scaled to provide a buoyancy force of $6 \mathrm{MN}$ (for one whole buoyancy body). The maximum stress occurrence (Von Mises stress, SEQV) in the total structure should not exceed $200 \mathrm{MPa}$; this arbitrary and conservative stress value is derived from standards [29]. Both the buoyancy and stress constraints are subject to a certain tolerance.

As said in Section 3.2, the relevant design loads are tendon rope loads and hydrostatic water pressure loads from changing water level. The loads were derived by performing a multi-body load simulation using FLEX5 according to design standards [28] for a multimega watt wind turbine mounted on a GICON ${ }^{\circledR}$-TLP scaled to provide the same buoyancy force considered. The maximum mooring force $F_{\text {moor }}$ as well as the maximum wave height $W_{h}$ obtained are then used for the loads applied in the FEA and the optimization process.

Table 6. Boundaries of the design space, constraints and loads values used as inputs for the given study case.

\begin{tabular}{|c|c|c|c|c|c|}
\hline Design Variable & Input & Unit & Constraint & Input & Unit \\
\hline$L$ & {$[8,15]$} & $\mathrm{m}$ & $F_{\text {buoy }}^{\text {min }}$ & $6-1 \%$ & $\mathrm{MN}$ \\
\hline$d_{i}$ & {$[2,4]$} & $\mathrm{m}$ & $\sigma_{\max }$ & $200+1 \%$ & $\mathrm{MPa}$ \\
\hline$d_{0}$ & {$[10,15]$} & $\mathrm{m}$ & & & \\
\hline$t_{i}$ & {$[0.02,0.15]$} & $\mathrm{m}$ & & & \\
\hline$t_{o}$ & {$[0.05,0.1]$} & $\mathrm{m}$ & & & \\
\hline$\alpha^{t o p}, \alpha^{b o t}$ & {$[0,30]$} & $\circ$ & Load & Input & Unit \\
\hline$C_{\text {exp }}^{t o p}, C_{\text {exp }}^{b o t}$ & {$[1,3]$} & - & $F_{\text {moor }}$ & 10 & $\mathrm{MN}$ \\
\hline$t_{c}^{t o p}, t_{c}^{b o t}$ & {$[0.15,0.5]$} & $\mathrm{m}$ & $W_{h}$ & 5 & $\mathrm{~m}$ \\
\hline$t_{s}^{t o p}, t_{s}^{b o t}$ & {$[0.01,0.04]$} & $\mathrm{m}$ & & & \\
\hline
\end{tabular}

\subsection{Results Using the Cumulative Multi-Niching Genetic Algorithm}

The results shown in this section are obtained using the CMNGA with the parameters presented in Table 7. The evolution through the optimization process of the objective function (the cost of the whole UBB in thousands of euros $(\mathrm{k} €)$ ) and the constraints values associated, are shown in Figure 10. Table 8 summarizes the optimized design variables of the UBB obtained, as well as its total cost and the value of the respected constraints.

Table 7. Parameters of the Cumulative Multi-Niching Genetic Algorithm used.

\begin{tabular}{lcccccccc}
\hline Parameter & $n_{\text {pop }}$ & $n_{\text {max }}$ & $n_{\text {gen }}$ & $n_{\text {crossover }}$ & $n_{\text {mutation }}$ & $n_{\text {min }}$ & $n_{\text {pool }}$ & $\eta_{C}$ \\
Input & 50 & 3000 & 500 & 40 & 10 & 25 & 30 & 15 \\
\hline
\end{tabular}



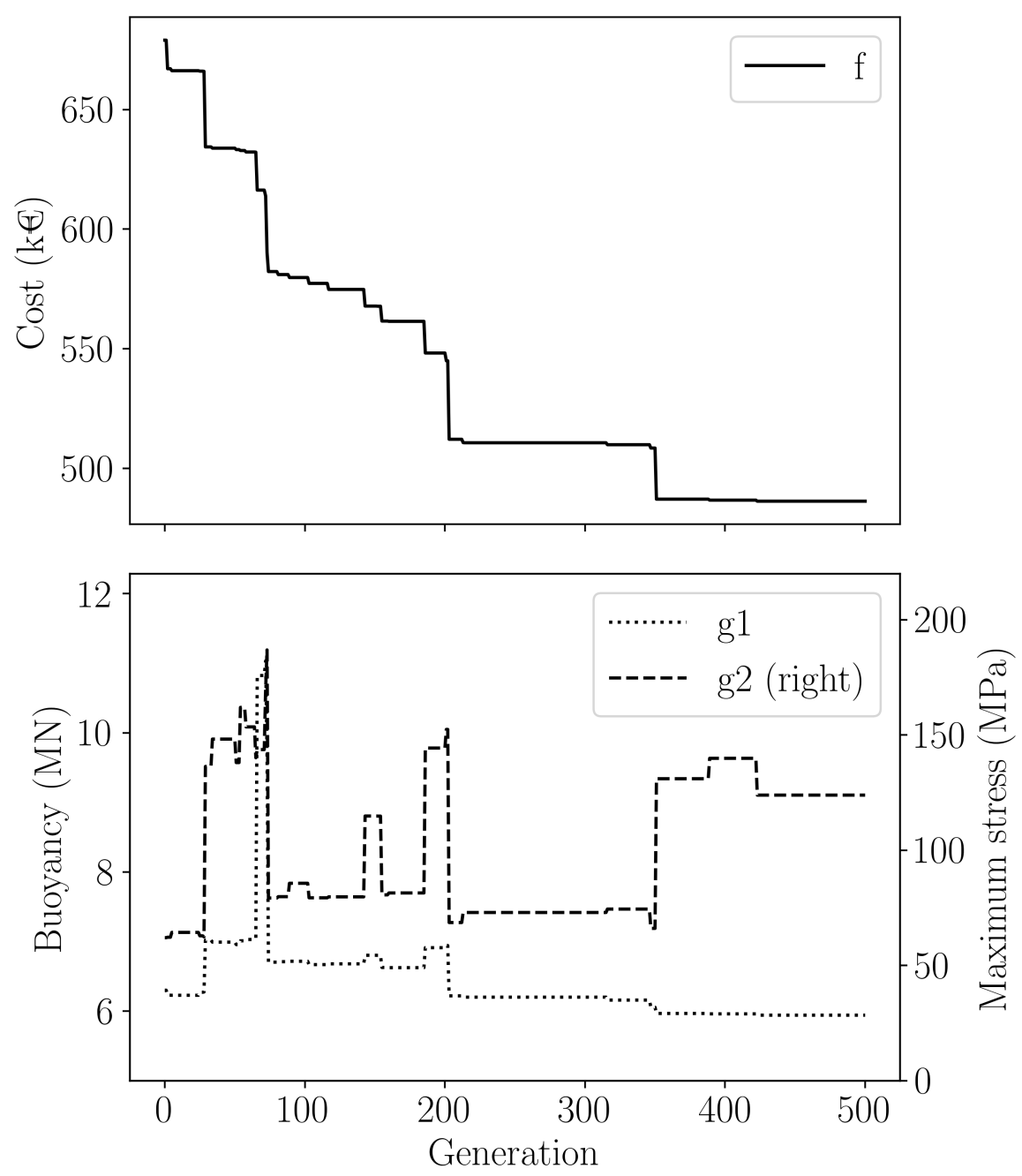

Figure 10. Evolution of the cost of the UBB during the optimization process with the CMNGA.

Table 8. Design variables, cost and constraint values of the optimized UBB with the CMNGA.

\begin{tabular}{ccccc}
\hline$L$ & $d_{i}$ & $d_{o}$ & $t_{i}$ & $t_{o}$ \\
$8.717 \mathrm{~m}$ & $2.085 \mathrm{~m}$ & $11.322 \mathrm{~m}$ & $26 \mathrm{~mm}$ & $57 \mathrm{~mm}$ \\
$\boldsymbol{\alpha}^{\text {top }}$ & $C_{\text {exp }}^{\text {top }}$ & $\boldsymbol{t}_{c}^{\text {top }}$ & $\boldsymbol{t}_{\boldsymbol{s}}^{\text {top }}$ & \\
$20^{\circ}$ & 2.64 & $190 \mathrm{~mm}$ & $14 \mathrm{~mm}$ & \\
$\alpha^{\text {bot }}$ & $C_{\text {exp }}^{\text {bot }}$ & $\boldsymbol{t}_{c}^{\text {bot }}$ & $\boldsymbol{t}_{\boldsymbol{s}}^{\text {bot }}$ & $19 \mathrm{~mm}$ \\
$2^{\circ}$ & 1.45 & $413 \mathrm{~mm}$ & & \\
$f$ & $g_{1}$ & $g_{2}$ & \\
$460.601 \mathrm{k€}$ & $5.942 \mathrm{MN}$ & $123.905 \mathrm{MPa}$ & \\
\hline
\end{tabular}

\subsection{Results Using a Basic Genetic Algorithm}

The results shown in this section are obtained using the basic GA with the parameters presented in Table 9. The evolution through the optimization process of the objective function and the constraints values associated, are shown in Figure 11. Table 10 summarizes the UBB optimized design variables as well as its total cost and the value of the respected constraints. 
Table 9. Parameters of the basic Genetic Algorithm used.

\begin{tabular}{lccccccc}
\hline Parameter & $n_{\text {pop }}$ & $n_{\text {gen }}$ & $n_{\text {parents }}$ & $n_{\text {pool }}$ & $\eta_{C}$ & $r_{\text {crossover }}$ & $r_{\text {crossover }}$ \\
Input & 50 & 300 & 10 & 30 & 15 & 0.8 & 0.2 \\
\hline
\end{tabular}
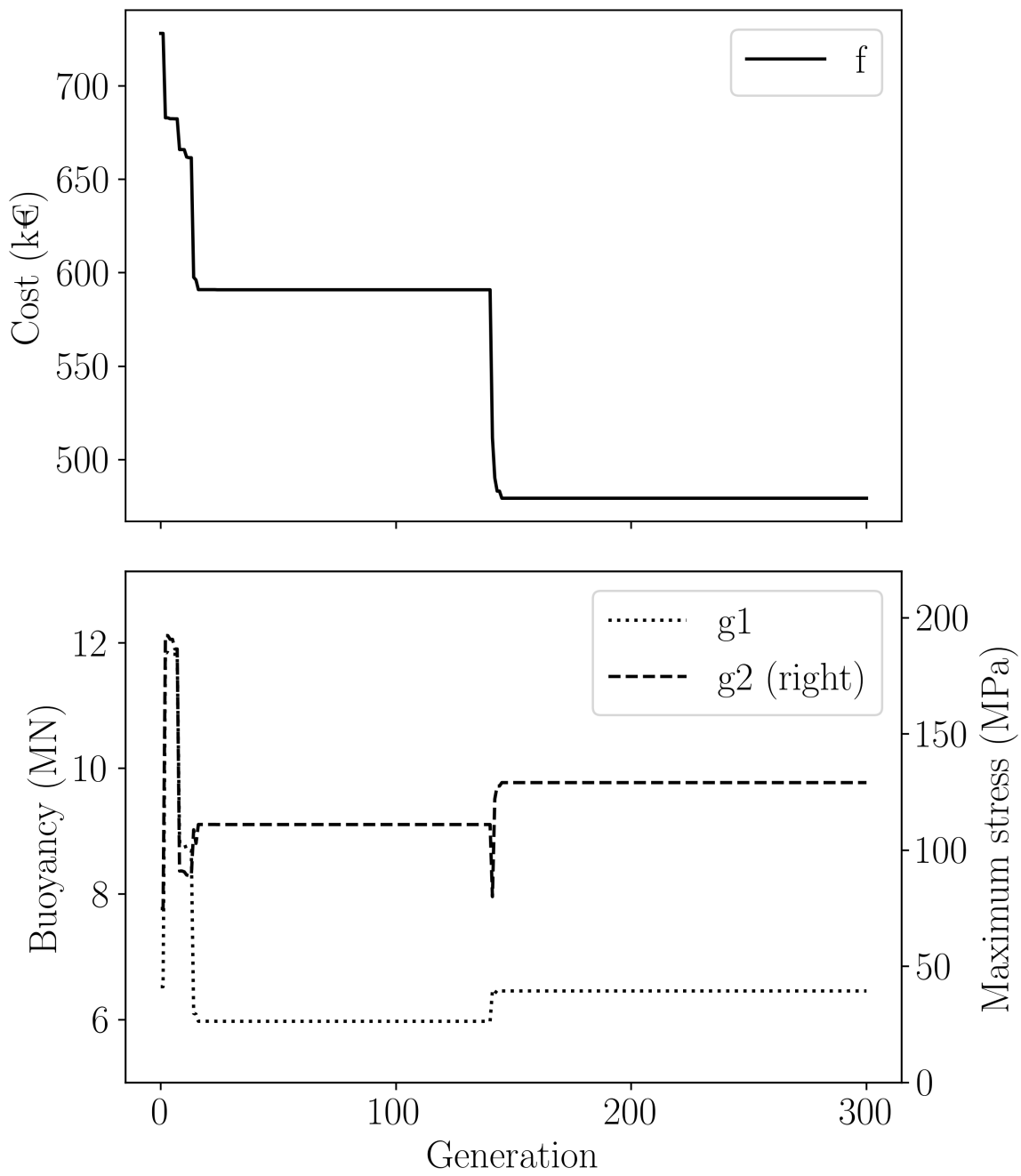

Figure 11. Evolution of the cost of the UBB during the optimization process with the basic GA.

Table 10. Design variables, cost and constraint values of the optimized UBB with the basic GA.

\begin{tabular}{ccccc}
\hline$L$ & $d_{i}$ & $d_{o}$ & $t_{i}$ & $t_{o}$ \\
$8.156 \mathrm{~m}$ & $2.906 \mathrm{~m}$ & $11.551 \mathrm{~m}$ & $34 \mathrm{~mm}$ & $55 \mathrm{~mm}$ \\
$\alpha^{\text {top }}$ & $C_{\text {exp }}^{\text {top }}$ & $t_{c}^{\text {top }}$ & $t_{s}^{\text {top }}$ & \\
$23^{\circ}$ & 2.03 & $268 \mathrm{~mm}$ & $10 \mathrm{~mm}$ & \\
$\alpha^{\text {bot }}$ & $C_{\text {exp }}^{\text {bot }}$ & $t_{c}^{\text {bot }}$ & $t_{s}^{\text {bot }}$ & \\
$8^{\circ}$ & 2.54 & $167 \mathrm{~mm}$ & $23 \mathrm{~mm}$ & \\
$f$ & $g_{1}$ & $g_{2}$ & & \\
$479.314 \mathrm{k€}$ & $6.458 \mathrm{MN}$ & $129.069 \mathrm{MPa}$ & & \\
\hline
\end{tabular}

\subsection{Comments and Comparison}

Globally, both results shown in Sections 4.2 and 4.3 attest of the good implementation of the optimization framework developed in this study. The evolution of the fitness function 
and the constraints, obtained with both GA, are shown in Figures 10 and 11. For every generation through the optimization process, the individual with the best fitness (the lowest cost) is identified and its fitness and constraints' values are plotted. The cost of one whole UBB is minimized throughout the optimization process and the constraints values verify both the buoyancy and stress limits defined previously.

The optimized designs obtained with both GA are shown in Tables 8 and 10 and are relatively similar. The optima found have both geometries presenting conical covers with greater angles for the top covers of around $20^{\circ}$. Similarly, the steel layers in the covers for both results are comparable as they are thicker for the bottom cover and relatively thin compared to the upper boundary of the design space. Results obtained for the concrete layer in the covers slightly differ; however, when considering the expansion coefficient and the concrete thickness, they are comparable. The conical covers allow the UBB to have a greater buoyancy force compared to a flat cover UBB with a similar mass, and to a certain extent, reduce the maximum stress in the structure. The expansion of the concrete layer towards the inner pipe helps also to reduce the stress in the structure. Results for the other design variables regarding the inner pipes and outer pipes of the UBB structure are similar for both GA. Values for the length of the UBB, the diameters and thickness of the pipes are close to the lower boundaries of the design space. This is expected as the objective here is to minimize the cost of the UBB, which is proportional to its mass, and thus to its volume. The geometry of the optimized UBB presented in Table 8 is shown Figure 12 as well as some of the results of the structural analysis with Ansys ${ }^{\circledR}$ for illustration.

As mentioned before, the CMNGA is able to identify multiple local optima in the design space. In the present study case, the optimization carried out with the CMNGA lead to similar design of the UBB but with a higher cost and different values for the buoyancy and stress constraints. With a different design space or other objective function and constraints, optima's designs might diverge more from results of the optimum, and be more interesting to highlight.
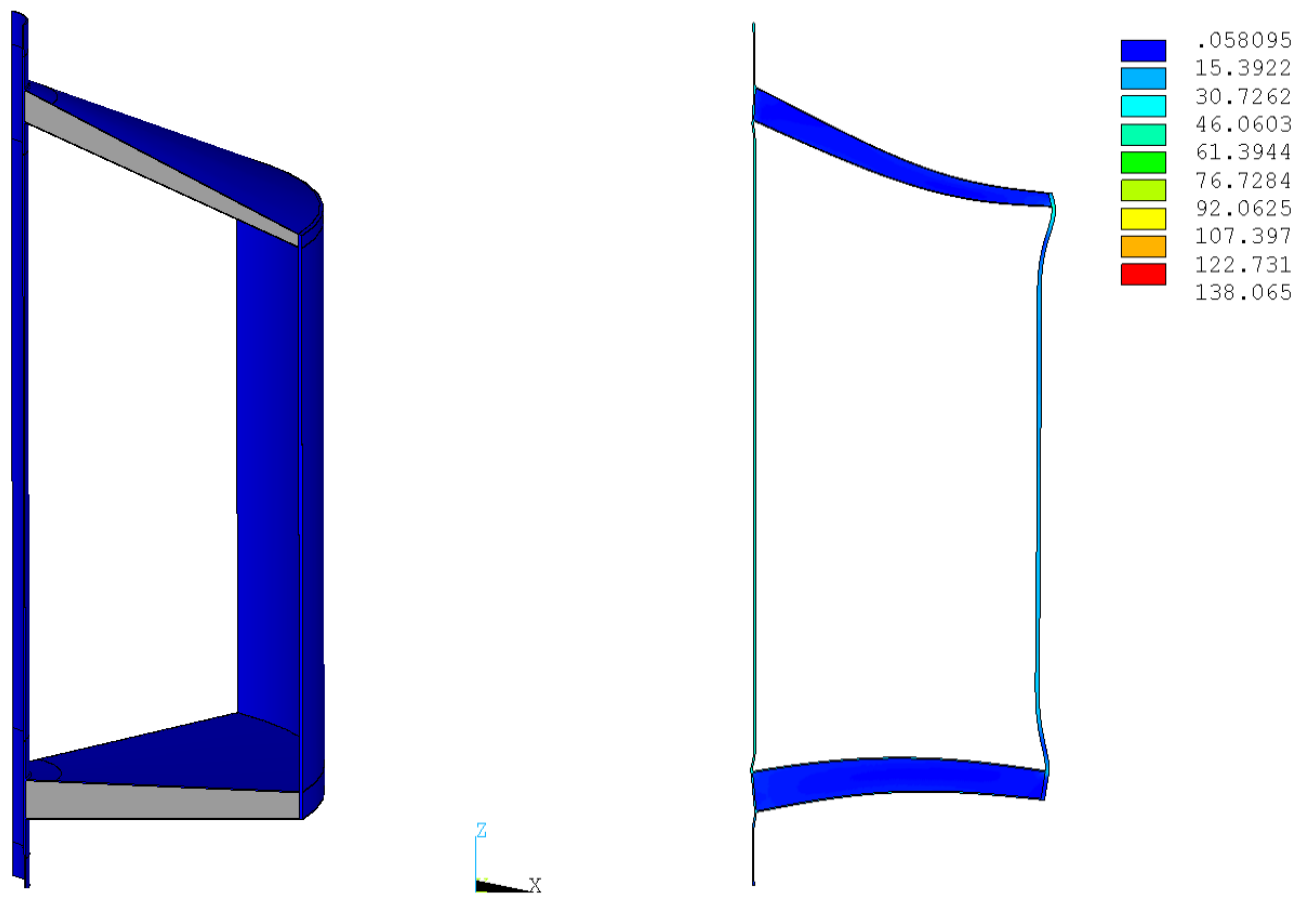

Figure 12. A 3D view of the optimized UBB (left) and Von Mises equivalent stress distribution (in $\mathrm{MPa}$ ) in the structure (right).

In terms of computational efficiency, the present optimization framework is relatively slow. Indeed, the structural analysis performed with Ansys ${ }^{\circledR}$ requires a non-negligible computation time (approximately 10 to $15 \mathrm{~s}$ ) whenever the objective function is computed 
and the constraints are checked. For the presented results, Intel ${ }^{\circledR}$ Xeon Gold 6130 at $2.10 \mathrm{GHz}$ was used. For a wide design space and many design variables as it is presented in this study case, the computation time is approximately more than half a day for both GA with around 4000 fitness function evaluations. Table 11 summarizes the computational time and the number of fitness function evaluation required by each algorithm in order to obtain the results shown in the previous sections. In order to obtain similar results, the CMNGA used fewer fitness function evaluations and therefore needed less computation time when compared to a basic GA. These results highlight the advantages of the CMNGA with regard to its ability to reduce the number of objective function evaluations required to reach a given solution, by avoiding unnecessary evaluation of a potential UBB design which, in the end, leads to a waste of computation time.

Table 11. Computational time and fitness function evaluation comparison for both GA used.

\begin{tabular}{lcc}
\hline & Basic GA & CMNGA \\
\hline Fitness function evaluations & 4500 & 3000 \\
CPU time (s) & 62,200 & 40,600 \\
\hline
\end{tabular}

At the end of the optimization process, the final population obtained with the CMNGA showed a great diversity in terms of design variables of the different individuals. In Figure 13, the scatter distribution of each design variable of all the individuals of the final population obtained with the CMNGA, is shown.
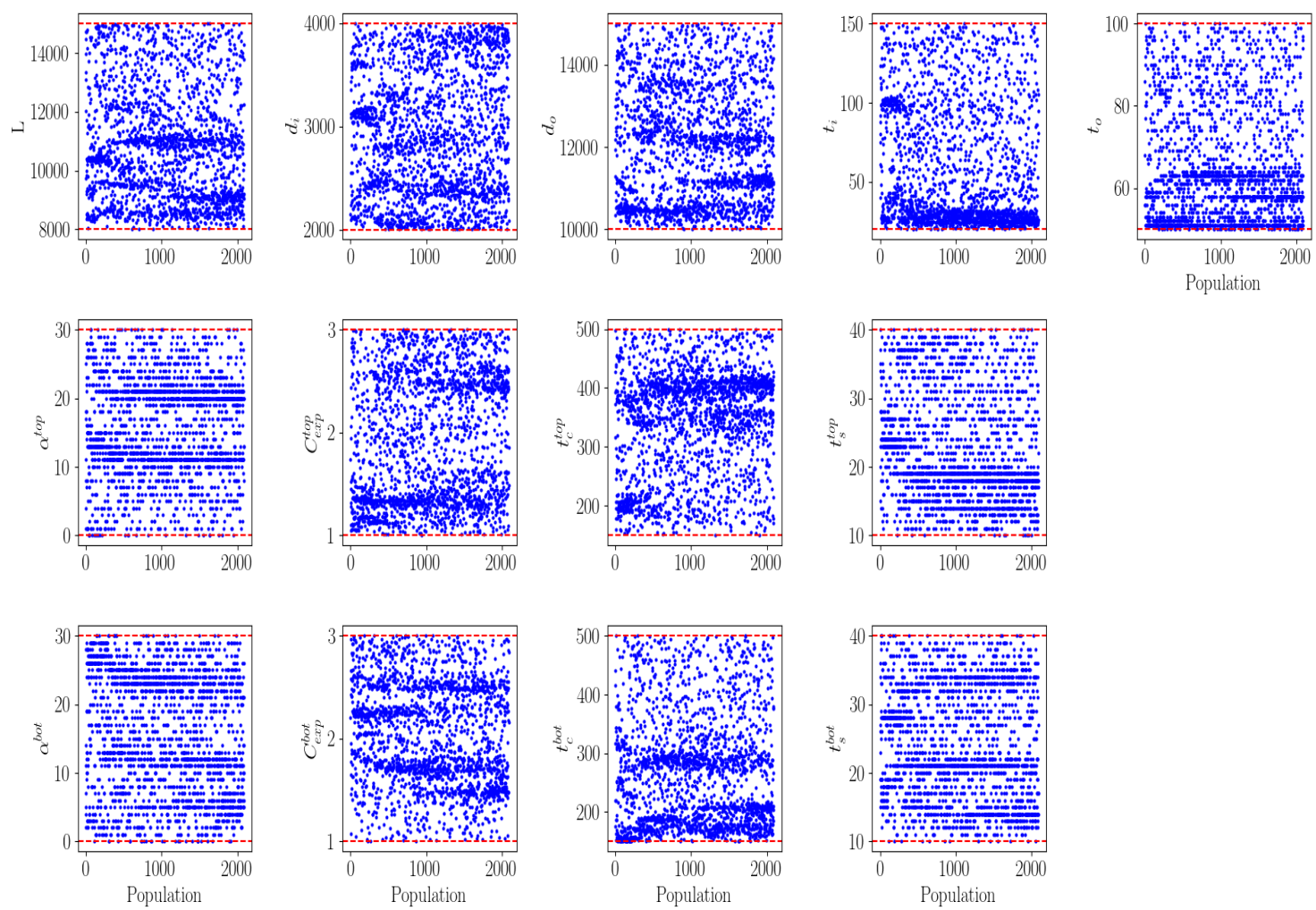

Figure 13. Population's design variables scatter distribution using the CMNGA and the results shown in Section 4.2. Boundaries of the design space are represented in red dashed lines.

As the population size increases, it is getting denser in the promising region of the design space, leaving other, less fit regions with fewer individuals. For some design variables, the optimum value is clearly identified, whereas for others, local optima values are equally 
considered, highlighting again all the advantages of the CMNGA. It is possible to compare this scatter distribution to the results obtained with the basic GA, even if the population size is fixed for this algorithm, by keeping track of every UBB design evaluated each generation. This leads to a very uniform distribution of the overall population's design variables, due to the evaluation of overly similar individuals, which is prevented in the CMNGA.

Finally, it is important to notify that with evolutionary algorithms, every optimization run cannot be the same as the previous one, because of the randomness of these optimization techniques. For the presented results, many optimization runs have been performed with both algorithms, leading most of the time to similar results but different algorithms' performance. Moreover, the results obtained in the end are quite sensitive to the design space, constraints and loads' value for the structural analysis; therefore, a certain control of these parameters is necessary in order to have confidence in the optimization results.

\subsection{Cost Reduction Potential}

As mentioned before, the presented optimization work is focused on the GICON ${ }^{\circledR}$ TLP, for which the buoyancy bodies were designed to provide each a buoyancy force of approximately $6 \mathrm{MN}$. In order to asses the potential cost reduction, the optimized UBB is compared to an old ship structure-oriented buoyancy design for the same buoyancy force and the UBB design first presented in [3]. Experience values for the mass of the old GICON $^{\circledR}$-TLP ship structure-oriented buoyancy body (of the considered buoyancy force) can be assumed to be around $150 \mathrm{t}$. According to [3], the steel and concrete mass of the UBB is about 2.6 times higher than the steel weight of this previous buoyancy body and 0.8 times cheaper due to lower manufacturing costs. By considering the manufacturing and material costs implemented in this study (see Table 2), Table 12 summarizes the simple cost reduction computation that could be expected using the optimized UBB design for the GICON $^{\circledR}$-TLP. These results confirmed the assumption made in [3] of a plausible $25 \%$ or more cost reduction after optimization of the UBB design.

Table 12. Cost reduction for the different buoyancy bodies of the GICON ${ }^{\circledR}$-TLP.

\begin{tabular}{lccc}
\hline & Old BB & UBB & UBB Optimized \\
\hline Weight (t) & 150 & 390 & 310 \\
Cost (ke) & 675 & 540 & 460 \\
Cost reduction (\%) & - & $20 \%$ & $32 \%$ \\
\hline
\end{tabular}

\section{Discussion and Conclusions}

In order to limit global warming, it is crucial that conventional fossil energies are, step by step, replaced by renewable energies, which have been in the spotlight in recent years, but are still somehow neglected. Floating offshore wind is trending more and more, and cost efficiency must be attained in order to tap the world's offshore wind resources in deep waters, for which fixed offshore wind turbines are not economically and technically viable. Recently, different floater concepts and modular components have been developed with the aim of reducing the production cost by serializing the fabrication procedure of floating offshore substructure. In addition, many academic and industrial research works have been performed on the design optimization of FOWT, particularly on their floating foundations.

This study presented an optimization framework specifically implemented for the design optimization of the UBB, a particular cylindrical buoyancy body design which enables a relatively fast manufacturing process and fits into different structural floater concepts. Some of the already existing academic and industrial work with regards to design optimization of floating substructures have been reviewed and summarized in the first part, before presenting the optimization process which is at the core of this study. The presented optimization framework implemented in Python couples two structurally different GA and the validated FEA tool Ansys ${ }^{\circledR}$. Preliminary results for a given study case 
have been obtained, leading to a cost-optimized UBB design with conical covers that respect the buoyancy and structural strength constraints defined. The results of both algorithms, a basic GA and the CMNGA, have been compared, particularly highlighting the efficiency of this optimization process in terms of fitness function evaluations. The particular design of this UBB and its fabrication process has a great potential to significantly reduce costs and manufacturing time of FOWT foundations. In addition, with the presented design optimization framework, a potential cost reduction of around $30 \%$ can be expected.

Further improvements are planned for the work presented in this study. The next step is first to increase the design level of the UBB towards the detailed design stage. The model and the structural analysis performed to ensure the UBB structural strength is relatively simple. Further improvement will be focused on including other structural loads, such as hydrodynamic loads, particularly when these loads are becoming important for a certain type of floating substructure. By increasing the level of the model and the analysis to the whole FOWT system including the whole platform, the turbine and the mooring, an integrated design optimization approach, for different limit states according to offshore standards, could be performed.

Similarly to the GICON ${ }^{\circledR}$-TLP, the design of the UBB is evolving due to its relatively new development. For example, a cast part for the inner pipe is currently under analysis in order to avoid having welds close to the inner pipe where the stress is relatively higher than in the rest of the structure. This new structural model would need to be implemented and the analysis changed, in consequence. The implementation of the UBB into floating substructures is not limited to TLP. The integration of this particular cylindrical buoyancy body into other floating foundations such as semi-submersible or even spar platform should be investigated and then optimized.

The cost model implemented in this study is simple and only includes experience values for manufacturing and material costs. The cost model could be improved including other types of costs depending on not only the mass of the structure but also other designrelated parameters or the installation process. Developing a robust and detailed cost model is not an easy task as data is often not published or available. Research is currently being made on a cost model for floating offshore wind within the FLOAWER consortium, which will potentially benefit other studies like this one.

The optimization framework presented in this work showed some space for possible improvements. One of its major issues is the computation time. Batch analysis could be implemented in order to evaluate potential designs in parallel. With regards to the GA used, their parameters are fixed throughout the optimization process, and it could be interesting to adapt their values. Moreover, different genetic operators or constraints handling techniques could be studied and integrated in this framework. In addition, other evolutionary algorithms could be implemented, leading to potential computation time savings. Finally, in order to improve the UBB optimization tool presented in this work and to help future users, a graphical user interface might be interesting to implement.

Author Contributions: Methodology, V.B. and F.A.; software, V.B.; validation, V.B. and F.A.; writingoriginal draft preparation, V.B.; writing — review and editing, V.B. and F.A.; supervision, F.A.; project administration, F.A.; funding acquisition, F.A. All authors have read and agreed to the published version of the manuscript.

Funding: The Floating Wind Energy Network (FLOAWER) is a multidisciplinary network of early stage researchers, academics and industrial leaders aiming to train the new generation of scientists and to address floating offshore wind industry needs. This project has received funding from the European Union's Horizon H2020 research and innovation programme under the Marie SłodowskaCurie grant agreement $N^{\circ} 860579$. In addition, the authors would like to thank the Federal Ministry of Education and Research (BMBF) for the financial support through the funded project OWSPlus based on a decision of the German Bundestag FK: 03WKDC3B. 
Acknowledgments: The authors would like to thank GICON - Großmann Ingenieur Consult GmbH for taking the responsibility as the hosting institution for secondment and for providing the figures and basic buoyancy body models as examples to be optimized. We would furthermore like to thank Marco Lutz and Robert Kaden for their support with the structural analysis of the buoyancy body and the FEA models. We would also like to thank Matthew Hall for answering our questions, which helped us implement the CMNGA code in Python. Finally, a special thanks to all the research team at LWET and to Ilker Burak Sarialtin for his help during the many optimization tests performed.

Conflicts of Interest: The authors declare no conflict of interest. The funders had no role in the design of the study; in the collection, analyses, or interpretation of data; in the writing of the manuscript, or in the decision to publish the results.

$\begin{array}{ll}\text { Abbreviations } \\ \text { The following abbreviations are used in this manuscript: } \\ \text { LCoE } & \text { Levlized Cost of Energy } \\ \text { UBB } & \text { Universal Bouyancy Body } \\ \text { FOWT } & \text { Floating Offshore Wind Turbine } \\ \text { GA } & \text { Genetc Algorithm } \\ \text { TLP } & \text { Tension leg platform } \\ \text { CMNGA } & \text { Cumulative Multi-Niching Genetic Algorithm } \\ \text { NSGAII } & \text { Non dominated Sorting Genetic Algorithm II } \\ \text { SLOW } & \text { Simplified Low Order Wind Turbine } \\ \text { FEA } & \text { Finite Element Analysis } \\ \text { TS } & \text { Tournament Selection } \\ \text { RWS } & \text { Roulette Wheel Selection } \\ \text { SBC } & \text { Simulated Binary Crossover } \\ \text { APDL } & \text { Ansys }{ }^{\circledR} \text { Parametric Design Language } \\ \text { FLOAWER } & \text { Floating Wind Energy Network } \\ \text { LWET } & \text { Lehrstuhl für Windenergietechnik } \\ \text { GICON } & \text { Großmann Ingenieur Consult } \\ \end{array}$

\section{References}

1. Lee, J.; Zhao, F. Global Offshore Wind Report 2021; Technical Report; Global Wind Energy Council: Brussels, Belgium, 2021.

2. Rhodri, J.; Ros, M.C. Floating Offshore Wind: Market and Technology Review Prepared for the Scottish Government; Technical Report; The Carbon Trust: London, UK, 2015.

3. Lutz, M.; Walia, D.; Adam, F. Development of a universal useable and in series production manufacturable buoyancy body design for TLP and semi-submersible. In Developments in Renewable Energies Offshore, Proceedings of the 4th International Conference on Renewable Energies Offshore (RENEW 2020), Lisbon, Portugal, 12-15 October 2020; Taylor \& Francis Group: Abingdon, UK, 2020; pp. 709-716. [CrossRef]

4. Butterfield, S.; Musial, W.; Jonkman, J.; Sclavounos, P. Engineering Challenges for Floating Offshore Wind Turbines; National Renewable Energy Lab. (NREL): Golden, CO, USA, 2007.

5. Leimeister, M.; Kolios, A.; Collu, M. Critical review of floating support structures for offshore wind farm deployment. J. Phys. Conf. Ser. 2018, 1104, 012007. [CrossRef]

6. Andersen, M. Floating Foundations for Offshore Wind Turbines. Ph.D. Thesis, Aalborg University, Aalborg, Denmark, 2016.

7. Adam, F.; Behr, C.; Walia, D.; Ritschel, U.; Großmann, J. A Modular TLP Floating Substructure to Maximize the Flexibility within the Supply Chain. In Proceedings of the 27th International Ocean and Polar Engineering Conference, San Francisco, CA, USA, 25-30 June 2017.

8. Borg, M.; Jensen, M.; Urquhart, S.; Andersen, M.; Thomsen, J.; Stiesdal, H. Technical Definition of the TetraSpar Demonstrator Floating Wind Turbine Foundation. Energies 2020, 13, 4911. [CrossRef]

9. Muskulus, M.; Schafhirt, S. Design Optimization of Wind Turbine Support Structures-A Review. J. Ocean Wind Energy 2014, $1,12-22$. 
10. Tracy, C. Parametric Design of Floating Wind Turbines. Master's Thesis, Massachusetts Institute of Technology, Cambridge, MA, USA, 2007.

11. Bachynski, E.; Moan, T. Design considerations for tension leg platform wind turbines. Mar. Struct. 2012, 29, 89-114. [CrossRef]

12. Gilloteaux, J.; Bozonnet, P. Parametric Analysis of a Cylinder-like Shape Floating Platform Dedicated to Multi-Megawatt Wind Turbine. In Proceedings of the International Offshore and Polar Engineering Conference, Stavanger, Norway, 17-22 June 2014.

13. Fylling, I.; Berthelsen, P. WINDOPT: An Optimization Tool for Floating Support Structures for Deep Water Wind Turbines. In Proceedings of the International Conference on Offshore Mechanics and Arctic Engineering, Rotterdam, The Netherlands, 19-24 June 2011; pp. 767-776. [CrossRef]

14. Hall, M.; Buckham, B.; Crawford, C. Evolving offshore wind: A genetic algorithm-based support structure optimization framework for floating wind turbines. In Proceedings of the 2013 MTS/IEEE OCEANS-Bergen, Bergen, Norway, 10-14 June 2013; pp. 1-10. [CrossRef]

15. Hall, M.; Buckham, B.; Crawford, C. Hydrodynamics-based floating wind turbine support platform optimization: A basis function approach. Renew. Energy 2014, 66, 559-569. [CrossRef]

16. Karimi, M.; Hall, M.; Buckham, B.; Crawford, C. A multi-objective design optimization approach for floating offshore wind turbine support structures. J. Ocean Eng. Mar. Energy 2017, 3, 69-87. [CrossRef]

17. Leimeister, M.; Collu, M.; Kolios, A. A fully integrated optimization framework for designing a complex geometry offshore wind turbine spar-type floating support structure. Wind Energy Sci. 2022, 7, 259-281. [CrossRef]

18. Dou, U.; Pegalajar-Jurado, A.; Wang, S.; Bredmose, H.; Stolpe, M. Optimization of floating wind turbine support structures using frequency-domain analysis and analytical gradients. J. Phys. Conf. Ser. 2020, 1618, 042028. [CrossRef]

19. Rentschler, M.; Adam, F.; Chainho, P.; Krügel, K.; Vicente, P. Parametric study of dynamic inter-array cable systems for floating offshore wind turbines. Mar. Syst. Ocean Technol. 2020, 15, 16-25. [CrossRef]

20. Pillai, A.; Thies, P.; Johanning, L. Mooring system design optimization using a surrogate assisted multi-objective genetic algorithm. Eng. Optim. 2019, 51, 1370-1392. [CrossRef]

21. Lemmer, F.; Yu, W.; Müller, K.; Cheng, P. Semi-submersible wind turbine hull shape design for a favorable system response behavior. Mar. Struct. 2020, 71, 102725. [CrossRef]

22. Lemmer, F. Low-Order Modeling, Controller Design and Optimization of Floating Offshore Wind Turbines. Ph.D. Thesis, University of Stuttgart, Stuttgart, Germany, 2018.

23. Ojo, A.; Collu, M.; Coraddu, A. A Review of Design, Analysis and Optimization Methodologies for Floating Offshore Wind Turbine Substructures. 2021. Available online: https://papers.ssrn.com/sol3/papers.cfm?abstract_id=3936386 (accessed on 13 January 2022).

24. Martins, J.R.R.A.; Ning, A. Engineering Optimization Design; Cambridge University Press: Cambridge, UK, 2021.

25. Adam, F.; Myland, T.; Dahlhaus, F.; Großmann, J. GICON ${ }^{\circledR}-$ TLP for wind turbines-The path of development. In Proceedings of the 1st International Conference on Renewable Energies Offshore (RENEW 2014), Lisbon, Portugal, 24-26 November 2014; pp. 24-26.

26. Walia, D.; Schünemann, P.; Hartmann, H.; Adam, F.; Großmann, J. Numerical and Physical Modeling of a Tension-Leg Platform for Offshore Wind Turbines. Energies 2021, 14, 3554. [CrossRef]

27. ANSYS Mechanical APDL Element Reference; Technical Report Release 17.2; ANSYS, Inc.: Canonsburg, PA, USA, 2016.

28. DNVGL-ST-0119. Floating Wind Turbine Structures; Technical Report; Det Norske Veritas and Germanischer Lloyd: Bærum, Norway, 2018.

29. DNVGL-OS-C101. Design of Offshore Steel Structures; Technical Report; Det Norske Veritas and Germanischer Lloyd: Bærum, Norway, 2019.

30. DNVGL-OS-B101. Metallic Materials; Technical Report; Det Norske Veritas and Germanischer Lloyd: Bærum, Norway, 2019.

31. Zhong, J.; Hu, X.; Zhang, J.; Gu, M. Comparison of Performance between Different Selection Strategies on Simple Genetic Algorithms. In Proceedings of the International Conference on Computational Intelligence for Modelling, Control and Automation and International Conference on Intelligent Agents, Web Technologies and Internet Commerce (CIMCA-IAWTIC'06), Vienna, Austria, 28-30 November 2005; Volume 2, pp. 1115-1121. [CrossRef]

32. Deb, K.; Agrawal, R.B. Simulated Binary Crossover for Continuous Search Space. Complex Syst. 1995, 9, $115-148$.

33. Hall, M. A Cumulative Multi-Niching Genetic Algorithm for Multimodal Function Optimization. Int. J. Adv. Res. Artif. Intell. 2012, 1, 6-13. [CrossRef]

34. Jamil, M.; Yang, X.S. A Literature Survey of Benchmark Functions For Global Optimization Problems. Int. J. Math. Model. Numer. Optim. 2013, 4, 150-194 [CrossRef]

35. PyAnsys. 2022. Available online: https://docs.pyansys.com/ (accessed on 13 January 2022). 